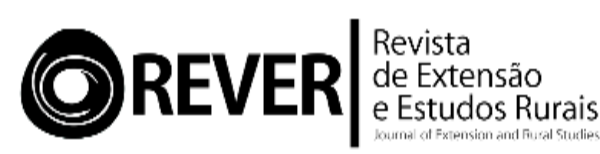

\section{Aspectos socioeconômicos da pesca artesanal no Estuário da Lagoa dos Patos (RS): Estudo de caso na Colônia de Pescadores Z-3}

\section{Socioeconomic aspects of the artisanal fishing in the Lagoa dos Patos (RS) estuary: Case study in the Fishermen's Colony Z-3}

\section{Vitória Daitx de Oliveira}

vick_daitx@hotmail.com

Graduada em Zootecnia pela Universidade Federal de Pelotas (UFPel). Mestranda do Programa de Pós-graduação em Aquicultura da Universidade Federal de Santa Catarina (UFSC).

\section{Flávio Sacco dos Anjos}

\section{saccodosanjos@gmail.com}

Graduado em Agronomia (UFPel). Doutor em Sociologia pela Universidad de Córdoba, España. Professor do Programa de Pós-Graduação em Sistemas de Produção Agrícola Familiar e do Programa de Pós-graduação em Sociologia (UFPel).

\section{Nádia Velleda Caldas}

velleda.nadia@gmail.com

Graduada em Ciências Sociais (UFPel). Doutora em Agronomia (UFPel). Professora do Programa de Pós-Graduação em Sistemas de Produção Agrícola Familiar (UFPel).

\section{Fernanda Novo da Silva}

fernandanovo@gmail.com

Graduada em Agronomia (UFPel). Doutora em Agronomia (UFPel). Bolsista PNPD Capes e Professora da Universidade Federal do Pampa - Campus Dom Pedrito. 


\title{
OREVER
}

\section{RESUMO}

Este artigo aborda a realidade da pesca artesanal no estuário da Lagoa dos Patos, mais precisamente na localidade correspondente à Colônia Z-3, situada no $2^{\mathbf{o}}$ distrito de Pelotas, Rio Grande do Sul. O foco da pesquisa foi justamente conhecer a realidade dos pescadores e das famílias que vivem desse ofício, bem como os principais problemas enfrentados e as soluções por eles apontadas. Os dados analisados revelaram que os grandes desafios recaem sobre os efeitos produzidos pela escassez da água salgada, pelo baixo preço pago pelo pescado, pelas leis que regulam a atividade, pelas normas que regem o período de defeso e pela diminuição progressiva do volume da pesca. O presente estudo se reveste de importância ao elucidar os principais entraves que atualmente limitam o desenvolvimento sustentável da atividade pesqueira dentro de uma zona carente de apoio público e privado, bem como de políticas públicas que melhorem as condições de vida da população que ali habita.

Palavras-Chave: Atividade Pesqueira; Colônia Z-3; Políticas Públicas.

\begin{abstract}
This article deals the reality of artisanal fishing in the Lagoa dos Patos estuary, more precisely in the locality corresponding to the Colony Z-3, located in the second district of Pelotas, Rio Grande do Sul. The focus of the research was precisely the reality of fishermen and families living in this craft, as well as the main problems faced and solutions pointed out by them. The data analyzed revealed that the major challenges lie in the effects of salt water scarcity, low price paid for fish, laws regulating activity, rules governing the closed season and progressive reduction of fishing volume. This study is important in elucidating the main obstacles that currently limit the sustainable development of fishing activity within a zone lacking public and private support, as well as public policies that improve the living conditions of the population that lives there.
\end{abstract}

Keywords: Fishing Activity; Colony Z-3; Public Policies. 


\section{OREVER}

\section{Introdução}

A atividade pesqueira é considerada um objeto de estudo bastante complexo, pois se trata de uma prática influenciada tanto por dinâmicas ambientais (regime pluvial, contaminação dos recursos hídricos, nível de salinização, etc.) quanto por fatores socioeconômicos e técnico-produtivos. Ademais, e não menos importante, também sofre influência da inter-relação que se estabelece entre a própria identidade dos pescadores artesanais e os ofícios ligados à pesca, assim como o próprio lugar onde ela se desenvolve.

A cadeia produtiva pesqueira é composta pelos segmentos da pesca extrativa marinha e da pesca extrativa continental (MPA, 2014). A soma desses segmentos à aquicultura permite que ambas se destaquem dentre as demais atividades agropecuárias desenvolvidas no Brasil e no mundo. Os dados oficiais mais recentes da produção mundial de pescado referem-se ao ano de 2014, sendo que as duas atividades totalizaram um montante de 167,2 milhões de toneladas (FAO, 2016). Desse total, a pesca extrativa - atividade que consiste na retirada de organismos aquáticos da natureza (DECKER, 2016) - contribuiu com 56\% (93,4 milhões), seja de forma industrial, amadora ou artesanal. Essa última modalidade corresponde ao foco deste estudo, o qual foi realizado com pescadores artesanais da Colônia Z-3 no município de Pelotas, Rio Grande do Sul (RS).

A atividade pesqueira artesanal é naturalmente praticada por produtores autônomos em toda a costa brasileira, estando marcada pela pouca utilização de tecnologia e pelo baixo poder de pesca (FAO, 1975), quando comparada ao ramo industrial. Apesar dessas características, ainda assim a pesca artesanal é responsável por mais da metade do pescado capturado no mundo (FAO, 2016), empregando, no Brasil, aproximadamente um milhão de pescadores, segundo informa o Registro Geral da Atividade Pesqueira (RGP). Num país de grandes desigualdades sociais, a pesca cobra protagonismo ao gerar oportunidades de trabalho e renda em diversas regiões de nossa geografia, tanto no âmbito lacustre quanto no marítimo.

Entretanto, apesar da grande extensão da costa brasileira e do seu potencial continental na extração de pescado, a pesca em geral, seja ela industrial seja artesanal, iniciada em pequena escala e desenvolvida a partir da expansão urbano-industrial, nas atuais circunstâncias, se encontra estabilizada em termos de produção (SILVA, 2014). Isso se deve a uma série de problemas, entre eles: os efeitos da poluição e da degradação dos ambientes aquáticos, bem como da especulação urbanística que avançou sobre comunidades pesqueiras. Tais fatores repercutem conjuntamente no sentido da 


\section{OREVER}

diminuição dos estoques de pescado e da qualidade da produção que chega à mesa dos consumidores. Esses problemas afetam diretamente os pescadores artesanais, os quais representam um grupo social ou uma coletividade que busca manter, sob um cenário invariavelmente adverso, "sua reprodução social através da apropriação direta dos recursos naturais" (PASQUOTTO, 2005, p. 10). Esse quadro geral se identifica plenamente com a situação atual dos pescadores artesanais que residem na Colônia São Pedro, popularmente conhecida como Colônia de Pescadores Z-3.

A Colônia Z-3 caracteriza-se por refletir uma relação muito peculiar entre homem, cultura e natureza. Encontra-se situada às margens da Lagoa dos Patos, no $2^{\circ}$ distrito de Pelotas (RS), e se organiza dentro de um espaço social de práticas arraigadas, relacionando-se com um ecossistema singular, que é responsável, entre outros aspectos, por regular o regime hidrológico numa imensa região ligada ao bioma pampa ${ }^{1}$. Aliás, foram esses fatos que permitiram o desenvolvimento da atividade pesqueira de caráter artesanal. Atualmente, segundo dados do Sindicato dos Pescadores de Pelotas (2018), cerca de 700 pessoas, dos 3.000 habitantes da comunidade, atuam como pescadores artesanais profissionais. Com isso, percebe-se que a Colônia Z-3 está organizada em torno da cadeia produtiva da pesca, a qual envolve as seguintes atividades: "saída para pesca, coleta de pescados, comercialização e manutenção de suprimentos e equipamentos de trabalho" (FIGUEIRA, 2009, p. 43).

O otimismo do comércio local e das diversas atividades econômicas ligadas direta ou indiretamente à pesca pode ser observado quando ocorrem boas safras de pescados no estuário da Lagoa dos Patos. Ao contrário disso, a diminuição na captura de pescados, por razões diversas, afeta fortemente a economia local, a qual está diretamente ligada à renda dos moradores. Nas atuais circunstâncias, a Colônia Z-3, assim como o sistema pesqueiro artesanal de modo geral, vem sofrendo crescentes dificuldades decorrentes da diminuição no volume de pescado, gerando grande preocupação por parte das pessoas que ali vivem, bem como das autoridades ligadas ao setor pesqueiro de Pelotas e região.

Se consideramos conjuntamente as colônias de pescadores de municípios próximos a Pelotas (São Lourenço e São José do Norte), chegaremos a um universo de

\footnotetext{
${ }^{1}$ A Laguna dos Patos é a maior laguna da América do Sul, estando situada no extremo sul do Brasil. Possui $265 \mathrm{~km}$ de comprimento e $60 \mathrm{~km}$ de largura em sua quota máxima, perfazendo uma superfície total de $10.144 \mathrm{~km}^{2}$. Suas dimensões extraordinárias e a ligação com o mar fazem com que seja referida como "mar de dentro", ainda que predominantemente esteja constituída, durante a maior parte do ano, por água doce. Segundo alguns geógrafos, a Lagoa dos Patos deveria ser referida como Laguna em virtude da ligação direta com o mar. Não obstante, o termo Lagoa está consagrado nas mais diversas alusões (ROSA, 1985).
} 


\section{OREVER|}

2.400 pescadores artesanais. Se, além disso, levarmos em conta o número médio de 3 pessoas vivendo em cada domicílio habitado por esses pescadores, chegaremos a um montante de 7.200 pessoas que dependem diretamente do que a lagoa lhes oferece.

A questão relativa à pesca artesanal se reveste de enorme importância na atual conjuntura, não somente em virtude da relevância social dessa atividade produtiva, mas também diante de aspectos de natureza econômica e cultural. Estudos, como o realizado por Musiello-Fernandes, Zappes e Hostim-Silva (2018), descrevem aspectos econômicos da pesca artesanal de camarões na franja atlântica do Brasil (nordeste e sudeste), mostrando a importância de gerar informação para a formulação de políticas públicas que assegurem a cogestão e a continuidade de uma atividade que integra a cultura dessas populações e de suas comunidades. Há trabalhos (CARDOSO; DOULA, 2016; 2018) que orientam a mirada para as perspectivas e limitações que a pesca reserva para jovens pescadores que dela dependem, para assegurar sua reprodução. Outro âmbito de análise consiste na abordagem da percepção dos agentes intervenientes (stakeholders) nas cadeias ligadas à pesca, a exemplo do estudo desenvolvido por Musiello-Fernandes, Zappes e Hostim-Silva (2017).

A principal agência da Organização das Nações Unidas produz documentos periódicos $(\mathrm{FAO}, 2014 ; 2016)$ que refletem uma clara preocupação com o estado atual das reservas piscícolas, em nível mundial, e também com a dinâmica de uma atividade responsável por garantir a segurança alimentar e nutricional de milhões de pessoas em todo o planeta.

Conhecer a realidade atual, os problemas e desafios de famílias de pescadores artesanais e da atividade como um todo, numa região específica do extremo sul do Brasil, foi o objetivo central deste estudo. Concomitantemente, como etapa deste mesmo trabalho, foi realizada uma caracterização do perfil socioeconômico dos pescadores, da cadeia produtiva e do processo de comercialização do pescado no âmbito da Colônia de Pescadores Z-3.

\section{Procedimentos metodológicos}

Estabelecidas algumas premissas iniciais, podemos avançar na apresentação dos instrumentos de coleta e análise dos dados. Foram realizadas, no período de abril a julho de 2017, vinte (20) entrevistas em profundidade com pescadores artesanais da Colônia Z3 , através do uso de roteiro semiestruturado. O critério de seleção dos entrevistados levou em conta o fato de serem efetivamente pescadores ativos, independentemente de 


\section{OREVER}

possuírem ou não o registro profissional. Nesse contexto, estão incluídos também os aposentados que ainda praticavam a atividade e pescadores que tinham outras fontes de renda além da pesca. As entrevistas foram executadas com o auxílio de um gravador, mediante prévia autorização dos informantes. O roteiro continha 43 perguntas (abertas e fechadas) que versavam sobre temas de ordem socioeconômica, além de dados sobre posse e uso de equipamentos técnicos, produção e comercialização de pescado, aspectos institucionais, problemas por eles suportados e soluções para as dificuldades enfrentadas pela atividade na comunidade.

Dentro desse recorte do universo analisado, a escolha dos participantes foi aleatória. Houve a contribuição de outros pescadores, de funcionários do Sindicato de Pescadores e de agentes da extensão rural oficial (Emater-RS) para mapear a localização e identificar pescadores que atendessem ao perfil desejado. Entre estes, era necessário saber os que se mostravam mais receptivos e participativos para, assim, contribuir na elucidação das indagações realizadas e disponibilização de informações e de elementos que retratassem fielmente a realidade.

A conformação da amostra foi estabelecida segundo a técnica do "ponto de saturação”, o qual é definido por Bauer e Gaskell (2002, p. 71) como o estágio no qual "temas comuns começam a aparecer, e progressivamente sente-se uma confiança crescente na compreensão do fenômeno", até que "o pesquisador se dá conta que não aparecerão novas surpresas ou percepções”, podendo determinar o fim do processo de coleta de dados. Através desta, chegou-se ao número de 20 entrevistas, num contexto de 700 pescadores registrados na comunidade.

Os roteiros e áudios foram transcritos em um diário de campo individual, com o objetivo de capturar exatamente a fala dos participantes, sobretudo em termos dos temas abordados nas questões. Após a digitação, as informações coletadas compuseram um banco de dados no formato estatístico Statistical Package Social Science (SPSS), através do qual, procedeu-se à análise dos dados mediante estatística descritiva, a fim de verificar a frequência das respostas obtidas.

Os resultados alcançados foram analisados a partir das seguintes categorias: 1) perfil socioeconômico dos pescadores artesanais da Colônia Z-3; 2) características da cadeia produtiva e da comercialização de pescado na Colônia Z-3; 3) perspectiva dos pescadores em relação aos problemas da atividade pesqueira na Colônia Z-3; e 4) perspectiva dos pescadores em relação às medidas para melhorar a atividade pesqueira na 


\section{OREVER/|}

Colônia Z-3. Expostas tais premissas, a seção seguinte irá abordar os resultados e a discussão dos dados da pesquisa.

\section{Resultados e discussões}

Os resultados e discussões serão apresentados considerando as quatro categorias de análise citadas no item anterior. Inicialmente, é identificado o perfil socioeconômico dos pescadores da Colônia Z-3, os aspectos relativos à estrutura da cadeia produtiva, bem como os principais meios de comercialização utilizados pelos entrevistados. Na sequência, trazemos à discussão as manifestações dos pescadores em relação aos problemas da atividade, finalizando com a indicação de medidas que, presumivelmente, poderiam amenizar os entraves encontrados na prática pesqueira realizada na Colônia Z3.

\section{Perfil socioeconômico dos pescadores artesanais da Colônia Z-3}

No grupo de pescadores entrevistados (18), 90\% são do sexo masculino e apenas duas entrevistadas (10\%), do sexo feminino. Esse aspecto reflete o grau de masculinização do setor pesqueiro, conforme salientado em alguns trabalhos, como os de Walter (2000) e Petrere Jr., Walter e Minte-Vera (2006). Apesar do escasso número de mulheres atuantes diretamente na captura do produto, a participação delas é predominantemente relatada em outras fases da cadeia produtiva do pescado, especialmente na etapa do beneficiamento.

O pescador da Colônia Z-3 tem idade média de 49,9 anos, variando entre idades que vão dos 22 aos 72 anos, sendo que mais da metade dos entrevistados (65\%) encontravam-se na faixa compreendida entre 40 e 59 anos. Diante disso, pode-se perceber que o ambiente da pesca artesanal da colônia vem envelhecendo, devido à ausência de jovens atuantes na atividade. Segundo Nierderle e Grisa (2006), em um estudo desenvolvido para analisar a formação e o desenvolvimento dessa colônia de pescadores, observou-se que muitos deles vêm buscando a inserção em outras atividades nas áreas urbanas, devido à situação de vulnerabilidade e incerteza em que se encontra a pesca nessa região do país.

A maior proporção de pescadores (85\%) reside na Colônia Z-3 há mais de 30 anos e cerca de $40 \%$ deles nasceram na própria comunidade, evidenciando uma baixa mobilidade no tempo e espaço, o que, segundo Santos (2005, p. 69), "pode ser atribuída às poucas oportunidades de trabalhos disponíveis na região" em torno da comunidade. 


\section{OREVER}

Com relação ao estado civil dos entrevistados, observou-se uma porcentagem maior de casados (80\%), sucedida pela proporção de solteiros (10\%), divorciados e viúvos, ambos com 5\% cada. Dos 20 entrevistados, apenas 5\% não possuíam filhos, sendo que $85 \%$ possuíam até quatro filhos e o restante tinha em média 2,65 filhos.

O número médio de pessoas por residência é de 4,05 e os domicílios são compostos, na maioria das vezes, pelo pescador, a esposa e os filhos. A média de familiares que dependem financeiramente da pesca é de 3,90, variando entre um único dependente até o total de oito pessoas por família.

A escolaridade do grupo entrevistado pode ser observada na Figura 1. Percebe-se que a grande maioria (80\%) relata possuir ensino fundamental incompleto. O restante se divide entre analfabetos, alfabetizados, mas que nunca frequentaram a escola, e os que possuem ensino médio incompleto. Somente um único entrevistado possuía ensino médio completo. Esse baixo índice de escolaridade entre os adultos dessa comunidade já havia sido descrito por Sacco dos Anjos et al. (2004) em investigação focada no estudo das estratégias de reprodução social dos pescadores artesanais da Colônia Z-3, com ênfase no recurso à pluriatividade.

Figura 1: Gráfico da escolaridade dos pescadores artesanais entrevistados da Colônia de Pescadores Z-3

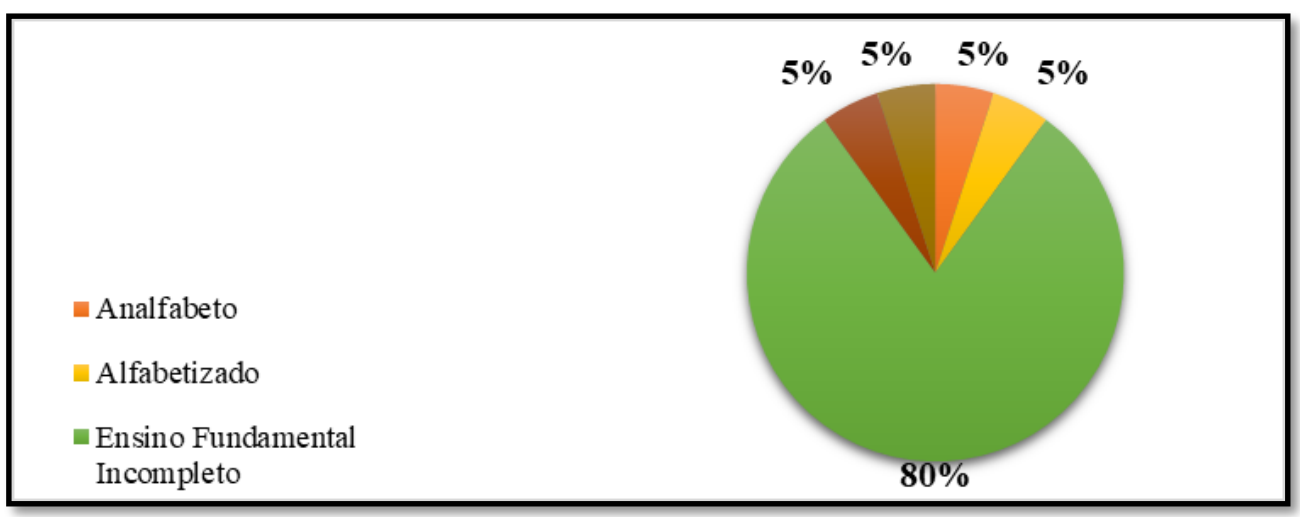

Fonte: Pesquisa de campo, 2017.

De acordo com Santos (2005), essa situação decorre do fato de que, na infância e adolescência dos pescadores das comunidades, o acesso e a permanência na escola eram mais difícil, quando comparado aos dias atuais. Para Ceregato e Petrere (2002), a falta de oportunidade em educação pode gerar uma resistência ou dificuldades na utilização de novas tecnologias pelos pescadores. Em alguns casos, estes não conseguem realizar o 


\section{QREVER e Estudos Rurais}

controle efetivo de sua produção, saindo muitas vezes prejudicados no momento da comercialização do produto por não possuírem conhecimentos elementares de cálculo (proporções, uso do dinheiro, etc.).

Entretanto, quando analisada a escolaridade dos filhos dos entrevistados (Figura 2), a situação apresenta-se bastante distinta, pois as crianças e os jovens atualmente têm maior acesso ao ensino básico e permanecem estudando até concluírem todas as etapas. Isso se deve ao incentivo dos próprios pais ao estudo, bem como ao fato de a Colônia Z3 possuir uma escola que oferece ensino fundamental, durante o período do dia, e ensino médio, durante a noite, para os moradores da comunidade.

Figura 2: Gráfico da escolaridade dos filhos dos pescadores artesanais da Colônia de Pescadores Z-3

- Cursando Ensino Fundamental

- Cursando Ensino Médio

Ensino Fundamental Incompleto

- Ensino Fundamental Completo

- Ensino Médio Completo

• Não estudam

Não respondeu

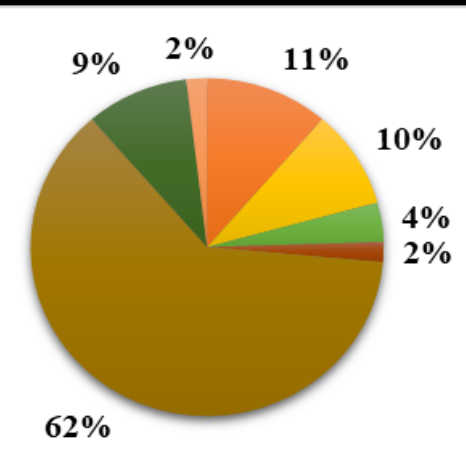

Fonte: Pesquisa de campo, 2017.

O tempo de exercício da profissão correspondeu a uma média de 32,15 anos de experiência, com a grande maioria dos entrevistados situando-se em um intervalo de 30 a 35 anos. Através da Figura 3, é possível verificar que a distribuição se mostra bastante ampla, variando de cinco a cinquenta anos. A amplitude de variação do tempo de serviço na atividade pesqueira foi igualmente observada por Ceregato e Petrere (2002) no Complexo de Urubupungá, que se estende pelos estados de São Paulo, Mato Grosso do Sul, Minas Gerais e Goiás. 


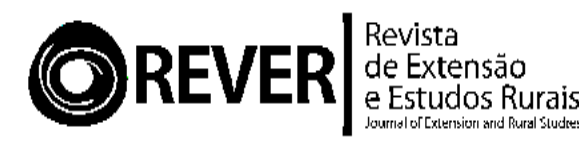

Figura 3: Gráfico do tempo de exercício da profissão de pescador artesanal na Colônia de Pescadores Z-3

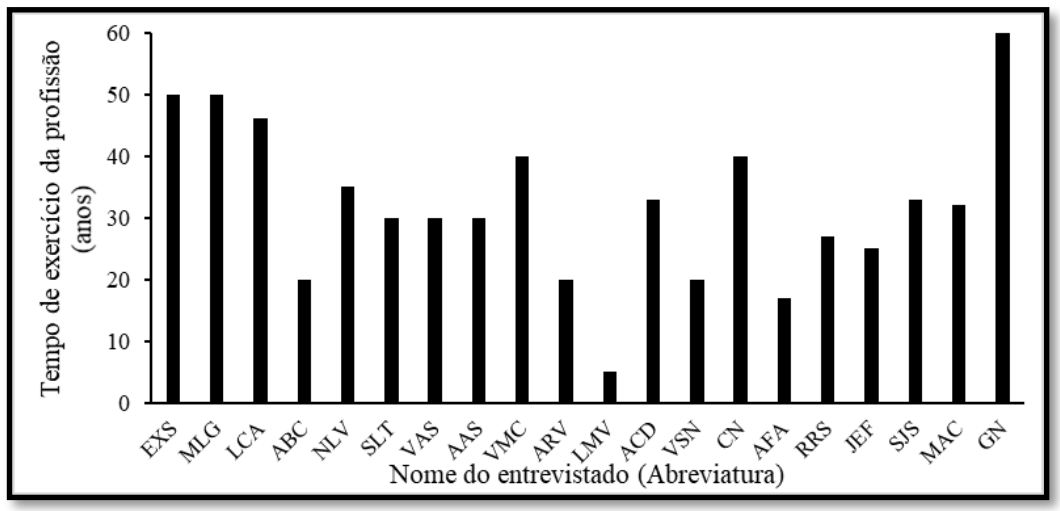

Fonte: Pesquisa de campo, 2017.

Com base nos depoimentos colhidos, foi identificada a renda mensal média dos pescadores entrevistados, obtida a partir da comercialização do pescado, a qual ascende a $\mathrm{R} \$ 956,25$, podendo variar de zero a $\mathrm{R} \$ 2.000,00$ por mês. Cabe explicitar que o valor de renda mensal igual a zero foi relatado somente pelos entrevistados que vivem exclusivamente da pesca de camarão, segmento este que se encontra em uma situação alarmante, pois, segundo os pescadores, o ano de 2017 foi o quarto ano consecutivo de frustração da safra. Esse acontecimento é explicado pelo fato de as condições climáticas estarem inadequadas, tendo em vista que o excesso de chuvas no período de outonoinverno acaba prejudicando a etapa de salinização do estuário, sendo este o fator essencial para a entrada do crustáceo na lagoa (pseudolarva). Somam-se a isso os "efeitos decorrentes da pesca predatória, a sobrepesca e a poluição, que, conjuntamente, acarretam a diminuição dos estoques dessa espécie” (BRAIODO e CAPORLINGUA, 2005, p. 185).

É possível observar que o valor médio da renda das famílias da Colônia Z-3 ultrapassa apenas em R \$ 19,25 o valor do salário mínimo. Em certa medida, esse dado se assemelha ao apurado pelo Instituto Brasileiro de Geografia e Estatística (IBGE), segundo levantamentos da Pesquisa Nacional por Amostra de Domicílios Contínua (PNAD Contínua) do ano de 2016, indicando que metade dos brasileiros têm renda em torno de um salário mínimo. Todavia, quando se compara o valor médio da renda domiciliar per capita dos brasileiros, equivalente a cerca de R\$ 1.226 (IBGE, 2016), com o valor da renda per capita obtida com a venda do pescado (aproximadamente $\mathrm{R} \$ 245,19$ ), verificase que o ganho dos pescadores representa quase um quinto da média nacional, demonstrando, assim, a situação de vulnerabilidade em que se encontram. Além disso, ao 


\section{OREVER/|}

se analisar os dados do IBGE referentes ao município de Pelotas, é possível observar que, apesar de o salário médio mensal dos trabalhadores formais ser de 2,8 salários mínimos, uma boa parcela da população do município $(31,9 \%)$ tem rendimento mensal per capita de até $1 / 2$ salário mínimo, demonstrando também uma situação de vulnerabilidade econômica de parte considerável dos habitantes da região. Virtude da baixa renda obtida exclusivamente com a atividade pesqueira, muitos pescadores acabam procurando outras atividades complementares à pesca, principalmente durante o período de defeso ${ }^{2}$, movimento que, segundo Sacco dos Anjos et al. (2004), é recorrente nas comunidades de pescadores artesanais da Lagoa dos Patos, configurando-se o que denominam como forma de pluriatividade ou de exercício de multiofícios, invariavelmente de caráter precário (ajudante de pedreiro, biscates, etc.).

Entretanto, no presente estudo, apenas $20 \%$ dos entrevistados relataram que realizam essa prática, incluindo atividades de eletricista, confecção de redes de proteção, construção civil e fretes. Com isso, em média, ocorre um acréscimo de $\mathrm{R} \$ 800,00$ na renda mensal da família. Por sua vez, mesmo com o baixo nível de renda e o descontentamento com o salário advindo da pesca, $85 \%$ dos pescadores responderam que gostam da sua profissão, exercendo-a com prazer. Consideram-se satisfeitos com a maneira com que vivem, por mais que enfrentem alguns problemas financeiros, o que vai ao encontro da teoria de Amartya Sen quando este destaca:

[...] a preocupação com a "qualidade de vida", a qual também se concentra no modo como as pessoas vivem (talvez até mesmo nas escolhas que têm), e não apenas nos recursos ou na renda de que elas dispõem (SEN, 2000, p. 39, aspas no original).

Ademais, o restante afirma estar na profissão porque isso "vem de família" ou mesmo por falta de outra opção de emprego ou ocupação.

Uma parcela majoritária (95\%) dos participantes da pesquisa corresponde a pescadores profissionais registrados. Em função disso, durante o período de proibição da pesca recebem um auxílio mensal do governo no valor de um salário mínimo - o SeguroDefeso $^{3}$-, que proporciona assistência financeira temporária aos pescadores artesanais.

Esse benefício é disponibilizado somente para pescadores que estão devidamente documentados junto ao Ministério do Trabalho (MTE) e em cumprimento às exigências

\footnotetext{
${ }^{2}$ Período de paralisação das atividades pesqueiras, visando a proteger as espécies durante a reprodução e, assim, garantir a manutenção dos estoques (DECKER, 2016).

3 É o benefício que todo pescador profissional devidamente documentado recebe, mediante parcelas mensais, na quantia de um salário-mínimo, em número equivalente ao período de paralisação (DECKER, 2016).
} 


\section{OREVER}

da Instrução Normativa MPA n 06, de 29 de junho de 2012. Além disso, a falta desse registro priva também o pescador de acessar serviços sociais, benefícios e crédito formal (KALIKOSKI e VASCONCELLOS, 2013). Dos entrevistados, 75\% recebem esse auxílio. Os $25 \%$ restantes não recebem o defeso devido ao fato de não serem pescadores registrados ou por estarem aposentados.

Os dados apresentados até aqui permitem conhecer alguns aspectos que retratam o perfil socioeconômico dos pescadores da Colônia Z-3, através de informações referentes tanto aos próprios entrevistados quanto aos domicílios aos quais estão vinculados. No entanto, faz-se necessário compreender, também, o funcionamento da cadeia produtiva, com ênfase na questão da comercialização dos produtos oriundos da atividade pesqueira realizada nessa comunidade.

\section{Características da cadeia produtiva e da comercialização de pescado na Colônia de}

\section{Pescadores Artesanais Z-3}

A cadeia produtiva da pesca (Figura 4) é composta por etapas que englobam desde a captura do pescado até a distribuição para o consumidor final, apresentando variações entre as diferentes comunidades pesqueiras. Primeiramente, toda e qualquer cadeia produtiva pesqueira inicia-se com a captura do pescado. No caso da colônia em estudo, essa prática é realizada na Lagoa dos Patos, com o auxílio de embarcações, motores e redes de pesca, sendo que $80 \%$ dos entrevistados são proprietários desses meios de produção. Após a captura, o produto é acondicionado no porão térmico da embarcação mediante a utilização de gelo. O acondicionamento sob baixa temperatura ajuda a manter o máximo de qualidade do produto durante o transporte até o desembarque para beneficiamento.

Segundo as informações obtidas, a quantidade de peixe capturado pelos pescadores artesanais entrevistados, em média, por semana, foi de $565 \mathrm{~kg}$. Entretanto, as respostas variaram bastante, apresentando valores desde 100 até $1.750 \mathrm{~kg}$ por semana. De acordo com o entrevistado EXS, essa diferença entre os valores é explicada devido à variação no número de redes utilizadas por cada pescador. Segundo suas palavras:

Quando eu cresci, mocinho, olhava a lagoa toda escura no verão né, hoje tô vendo uma lagoa no verão numa safra boa, uma cidade dentro do mar em alguns lugares. Aí a gente não tem nem noção, sabe assim, o fulano tem 200 redes, o outro tem 600 , o outro tem 90 , outro tem cento e poucas, números muito diferenciados (Pescador EXS, informação verbal, 2017). 


\section{(O)REVER|}

Dentro do montante de capturas, as principais espécies encontradas na Colônia Z3, durante o período de realização do estudo, foram tainha, corvina, linguado e bagre.

Conforme indica a Figura 4, a próxima etapa da cadeia consiste na comercialização do produto. Esta pode variar de acordo com cada pescador, podendo ser realizada de diversas formas, incluindo a venda para intermediários/atravessadores e a venda direta ao consumidor, às peixarias, feiras, cooperativas, entre outras modalidades. Neste estudo, constatamos três formas de comercialização (Tabela 1).

Figura 4: Cadeia produtiva da pesca, desde a captura até o consumidor

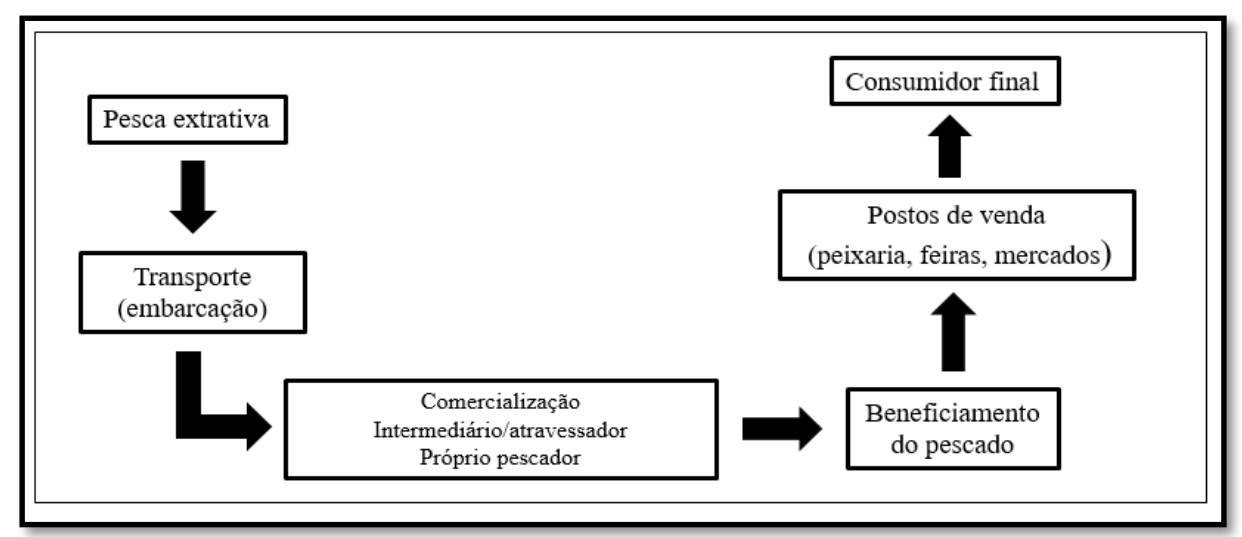

Fonte: Elaboração dos autores, 2017.

Tabela 1: Comercialização dos produtos pelos pescadores artesanais entrevistados na Colônia de Pescadores Z-3

\begin{tabular}{lcc}
\hline Comercialização do produto & $\begin{array}{c}\text { Frequência } \\
\text { absoluta }\end{array}$ & $\begin{array}{c}\text { Frequência } \\
\text { relativa (\%) }\end{array}$ \\
\hline Intermediários/atravessadores & 14 & 70 \\
\hline Intermediários/atravessadores e na própria casa & 5 & 25 \\
\hline Intermediários/atravessadores, na própria casa e na feira & 1 & 5
\end{tabular}

Fonte: Pesquisa de campo, 2017.

Percebe-se que a maior parte $(70 \%)$ dos pescadores entrevistados vende seu pescado diretamente para intermediários/atravessadores, mostrando a dependência do grupo em relação a esse canal de comercialização. Por meio dos relatos dos moradores, tal dependência é explicada pela falta de opções de compradores potenciais dentro da comunidade e pela carência de local adequado para estocar o pescado desembarcado para posterior comercialização. Assim, são eles obrigados a vender o pescado aos compradores de sempre, que geralmente impõem preços, comprometendo a renda do pescador. 


\section{OREVER|}

De acordo com Isaac-Nahum (2006), a pesca artesanal do litoral amazônico também apresenta essa dependência para com os intermediários/atravessadores, o que configura um dos principais entraves para a melhoria das condições de vida do pescador. A imposição dos compradores é comprovada pelos relatos de $90 \%$ dos entrevistados. Um dos pescadores, quando abordado sobre a estipulação do preço, reafirma essa situação, com as seguintes palavras:

É o comprador, a gente chega e ele dá o preço. A gente é obrigado a vender, mesmo descontente com o preço, se não apodrece. Porque a gente não tem aonde armazenar (Pescador GN, informação verbal, 2017).

Outro pescador, além de ressaltar novamente que a definição dos preços é efetuada pelo intermediário/atravessador, explicita a falta de outras opções de compradores na Colônia Z-3, o que torna os pescadores reféns das relações preexistentes:

A tainha esse ano aqui tava um e pouco, em Santa Catarina tava $\mathrm{R} \$$ 16,00. O mesmo comprador que comprava aqui compra lá a $\mathrm{R} \$ 16,00$, mas aqui ele decidiu que ia pagar tanto. Só que lá o mercado do pescado é bem mais fácil, lá tem empresa grande e pequena trabalhando. Aqui eles mataram as pequenas tudo, aqui não tem empresa pequena mais, aqui, ou trabalha com eles ou não trabalha com ninguém. Não tem pra quem vender (Pescador RRS, informação verbal, 2017).

Além disso, essa relação entre pescadores e intermediário/atravessador é mantida devido ao crédito disponibilizado para custeio das viagens (alimentação, óleo diesel e gelo) e manutenção dos equipamentos, tornando, assim, a produção do pescador completamente tributária desse comprador. Conforme o depoimento de alguns pescadores:

O salgueiro vem e tu pede seis e ele diz não te pago cinco. Tu é obrigada a vender. Ele te emprestou o dinheiro sem juro, sem nada, tudo fica na deles "o grandão" (Pescadora LCA, informação verbal, 2017, destaque nosso).

Ele fornece gelo, alimentação e o óleo para descontar na pescaria. E tem viagem que não tira pra pagar aquela despesa que levou. Aí fica devendo na próxima, e se na próxima não faz fica sempre devendo, não tem outra alternativa (Pescador VMC, informação verbal, 2017).

Apesar de uma parte significativa dos entrevistados considerar a negociação com os intermediários/atravessadores como a única forma de comercialização, percebe-se que $25 \%$ deles praticam também a venda na própria casa, e $5 \%$ utilizam a feira no centro urbano para comercializar seu produto. O objetivo, nesse caso, é obter um preço superior ao que é pago pelo intermediário. A fala a seguir mostra por que a comercialização ainda está associada ao intermediário/atravessador e não exclusivamente à venda no próprio domicílio, mesmo esta se mostrando mais rentável ao pescador. 


\section{OREVER/|}

Feita em pouca quantidade né, a gente tem pouco espaço pra processar e armazenar o peixe e o camarão em casa, mas sempre que tem, a gente faz. Porque daí o preço segue o do mercado (Pescador ABC, informação verbal, 2017).

Esse fato se repete em diversos relatos dos entrevistados, mostrando o interesse e a consciência da vantagem de realizarem eles próprios a comercialização do produto. Contudo, o entrave referente ao espaço físico, ao tempo despendido na realização do beneficiamento e ao meio de locomoção para transportar o pescado até o centro da cidade acabam desmotivando o pescador, fazendo com que opte pela venda para o intermediário/atravessador numa proporção muito elevada (70\%). Desse modo, o pescado é vendido 'inteiro', sem nenhum tipo de agregação de valor. O restante dos pescadores entrevistados informa que realizam o processo de filetagem ou a separação em postas quando vendem o produto em casa ou em feiras. Esse mesmo processo de transformação da matéria-prima é feito pelos intermediários/atravessadores.

Em relação aos valores ${ }^{4}$ recebidos em decorrência da venda dos principais produtos oriundos da pesca, quando comercializados através do intermediário/atravessador, o preço apresentou grande variabilidade entre as espécies encontradas no estuário (Quadro 1). No caso da tainha, o valor variou de R\$1,50 a R\$ 3,50/kg. Para a corvina, o linguado e o bagre, o preço oscilou entre $\mathrm{R} \$ 1,00$ a $\mathrm{R} \$ 2,50 / \mathrm{kg}$, $\mathrm{R} \$ 8,00$ a $\mathrm{R} \$ 10,00 / \mathrm{kg}$ e $\mathrm{R} \$ 1,00$ a $\mathrm{R} \$ 2,00 / \mathrm{kg}$, respectivamente.

Quadro 1: Média e desvio padrão do preço das principais espécies capturadas na Colônia Z-3

\begin{tabular}{ll}
\hline Espécie & Preço/kg \\
\hline Tainha & $2,65 \pm 0,46$ \\
\hline Corvina & $1,42 \pm 0,34$ \\
\hline Linguado & $8,67 \pm 1,15$ \\
\hline Bagre & $1,67 \pm 0,58$ \\
\hline
\end{tabular}

Fonte: Pesquisa de campo, 2017.

A média geral paga pelo quilo de peixe (todas as espécies) foi de $\mathrm{R} \$ 3,60$, valor considerado muito baixo por todos os entrevistados, quando comparado com o preço encontrado no comércio local. Após o beneficiamento, o pescado é armazenado para posterior transporte até o varejo, incluindo peixarias, mercados e restaurantes, onde serão vendidos ao consumidor final.

\footnotetext{
${ }^{4}$ Preço pago pelo peixe inteiro (com cabeça e vísceras), sem nenhum tipo de beneficiamento.
} 


\section{OREVER}

Nesta seção, foram apresentados dados e depoimentos referentes à dinâmica da cadeia produtiva pesqueira e às relações de comercialização travadas entres os atores envolvidos. Já a próxima, aborda os principais problemas da atividade, identificados pelos próprios pescadores artesanais que foram entrevistados na realização da pesquisa de campo.

\section{Perspectiva dos pescadores em relação aos problemas da pesca na Colônia Z-3}

Atualmente, a Colônia Z-3, bem como o sistema pesqueiro de modo geral, vem sofrendo dificuldades e desafios de ordem ambiental, social, institucional e econômica. Com a realização deste estudo, foi possível identificar os principais pontos críticos através dos depoimentos dos pescadores. Assim sendo, a Tabela 2 foi elaborada dentro desse esforço de compreensão da realidade. É preciso frisar que certos problemas estão relacionados uns com os outros, não podendo ser avaliados de forma desconectada ou individualizada.

As maiores dificuldades, na visão dos entrevistados, envolvem a escassez da água salgada (20,00\%), o baixo preço do pescado (17,5\%), as leis atuais, o período de defeso $(12,5 \%)$ e a diminuição do volume da pesca $(10,0 \%)$.

Tabela 2: Principais problemas relatados pelos pescadores artesanais entrevistados da Colônia de Pescadores Z-3

\begin{tabular}{lcc}
\hline Principais problemáticas da atividade & $\begin{array}{c}\text { Frequência } \\
\text { absoluta* }\end{array}$ & $\begin{array}{c}\text { Frequência } \\
\text { relativa (\%) }\end{array}$ \\
\hline Escassez da água salgada & 8 & 20,0 \\
\hline Baixo preço do pescado & 7 & 17,5 \\
\hline Leis e Período de defeso & 5 & 12,5 \\
\hline Diminuição do volume de pescado & 4 & 10,0 \\
\hline Preço do combustível & 2 & 5,0 \\
\hline Condições climáticas & 2 & 5,0 \\
\hline Falta de espaço físico para o beneficiamento do & 2 & 5,0 \\
pescado & 2 & 5,0 \\
\hline Intermediário/Atravessador & 2 & 5,0 \\
\hline Pouca opção de venda & 1 & 2,5 \\
\hline Despesas com a pesca muito altas & 1 & 2,5 \\
\hline Falta de gelo & 1 & 2,5 \\
\hline Fiscalização & 1 & 2,5 \\
\hline Universidade Federal do Rio Grande (FURG) & 1 & 2,5 \\
\hline PATRAM e IBAMA** & 1 & 2,5 \\
\hline Pesca predatória & & \\
\hline Número de vezes em que esse tema se repetiu na fala dos entrevistados, ou seja, um & \\
mesmo entrevistado pode ter apresentado mais de uma problemática. &
\end{tabular}




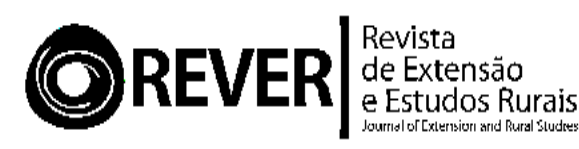

** Patrulha Ambiental da Brigada Militar e Instituto Brasileiro do Meio Ambiente e dos Recursos Naturais Renováveis.

Fonte: Pesquisa de campo, 2017.

Cabe informar que a escassez de água salgada na lagoa é um fenômeno natural, resultante do excesso de chuvas que acaba por elevar o nível dos rios que desaguam na lagoa, impedindo com que a água oceânica ingresse trazendo consigo as espécies de interesse econômico (CALLIARI, 1980), entre elas, especialmente, a forma jovem do camarão. Ou seja, trata-se de fatores que estão encadeados, gerando os problemas mencionados anteriormente. A importância desse fenômeno pode ser observada principalmente na fala de dois pescadores, quando indagados sobre os principais problemas da atividade: “A água salgada, porque tendo água salgada pra nós é melhor né. Água doce pra nós é crise total” (Pescador CN, informação verbal, 2017) e o "Clima né, não entrando a água salgada não tem pescaria, não tem fartura nunca" (Pescador ACD, informação verbal, 2017).

Todavia, essa questão da entrada da água salgada na Lagoa dos Patos pode estar associada a outros fatores que transcendem a temática do regime pluviométrico. Alguns depoimentos apontam os efeitos produzidos pela recente modificação dos molhes da Barra de Rio Grande, obra que facilitou as operações de carga e descarga no Porto de Rio Grande, mas que, por outro lado, prejudicou os estoques pesqueiros da lagoa. É através do Porto de Rio Grande que toda a produção de soja do sul do Brasil é exportada para fora do país, assim como outros tipos de mercadorias.

Para o entrevistado ABC, esse aspecto é o principal motivo, pois, segundo ele:

[...] faz cinco anos que eles mexeram nos molhes, desde então a pescaria vem diminuindo, porque a água da lagoa não tem pressão pra sair lá fora. Essa construção foi feita com a função de terem que ta dragando, por causa dos navios e o custo de dragar é muito alto. Só que agora a água não tem pressão pra sair e nem a água salgada tem pressão para entrar (Pescador ABC, informação verbal, 2017).

A segunda barreira à melhoria das condições de vida da população estudada diz respeito ao baixo preço pago pelo pescado, uma vez que, como citado anteriormente, o preço é regulado pelos intermediários/atravessadores. De acordo com todos os entrevistados, os compradores estabelecem preços muito baixos, lucrando bem mais que os próprios pescadores, que se encontram muitas vezes em condições de vulnerabilidade econômica e social. Os pescadores EXS e ACD, respectivamente, ressaltam nos seus depoimentos que: 


\section{OREVER}

Hoje a maior dificuldade é o preço, esse é o fundamental, não tem nada que te prejudique mais. A não valorização, porque tu vê, lá em 2000 e alguma coisa tu compravas um bujão $\mathrm{R} \$ 16,00-17,00$, hoje o bujão tá quase 60,00 é uma diferença né?! E o peixe continua o mesmo preço (Pescador EXS, informação verbal, 2017).

O preço tá nos matando, o preço não sobe nunca. Eu trabalhei com a tainha no ano de 2000, em 2000 ela tava R \$2,80, nós temo em 2017 já e ela tá R \$ 2,50, até diminuiu (Pescador ACD, informação verbal, 2017).

Analisando essas falas, é possível perceber que realmente os preços praticados representam um entrave para a atividade pesqueira, e que os valores dos produtos não acompanharam o aumento e a valorização dos outros bens de consumo, como citado acima. Concomitantemente a essa questão, quando os pescadores foram indagados sobre as dificuldades na comercialização do produto, novamente surgiram os temas relacionados ao preço, à falta de valorização e à exploração do intermediário/atravessador como aspectos recorrentes, o que pode ser verificado nos seguintes depoimentos:

Só pra tu ter uma noção, nós tamo entregando o bagre a dois real. O mesmo bagre que nós entreguemo pra ele a dois real, chega qualquer pessoa na salga dele, ele vai entregar a oito. E o pescador fica com toda a despesa, com óleo, gelo, comida, manutenção do motor e rede, e ele só tem o trabalho de simplesmente lavar as caixas que pesa o peixe, mais nada. O lucro é todo dele (Pescador ARV, informação verbal, 2017).

Porque acontece o seguinte, tu pega uma tainha que hoje tão vendendo 2,50 a grande, tu vai comprar no mercado ela tá quinze, quer dizer quem ganha é o atravessador o pescador nunca ganha nada. E assim acontece com todo mundo que produz (Pescador GN, informação verbal, 2017).

Outra dificuldade destacada pelos entrevistados corresponde às leis e ao período de defeso. Na visão de alguns pescadores, o sistema que rege o defeso possui falhas, não condizendo com o ciclo reprodutivo das espécies presentes na lagoa. De acordo com o pescador SLT, mesmo durante a proibição da pesca de certas espécies, elas estão presentes no estuário e os pescadores acabam capturando-as, mas não podem aproveitálas devido à proibição, tal como se demonstra nos depoimentos abaixo:

Eles não sabem nada! Aí eu vou largo uma rede pra tainha eu pego corvina, o que eu vou fazer com corvina, botar fora?! Aí eu pego a corvina eles me levam preso. Aí eu boto a rede pra pescar corvina pego tainha, a tainha é proibida (Pescador SLT, informação verbal, 2017).

Agora mesmo, a tainha é uma safra que vai ser boa e vão trancar, aí fica difícil né. Ai o bagre mesmo proibido dá uma baita pesca também. Safra boa que nem deu ano passado e teve que muita gente botar fora (Pescador LMV, informação verbal, 2017).

Tem muita coisa que atrapalha, umas leis que a gente não sabe como funciona. É igual a tainha, essa rede que tá aí é proibida, a malha 45, 


\section{OREVER/|}

mas a tainha que dá nela é a tainha que tá liberada. Eu não entendo como funciona, tem que ser o tamanho do peixe né, mas não eles liberam a rede (Pescador ACD, informação verbal, 2017).

Conclusão semelhante foi formulada por Decker (2016), em estudo realizado igualmente com moradores da Colônia Z-3, evidenciando o descontentamento da comunidade em relação ao período de proibição da pesca, pois, segundo ACD, "tem lei demais pra pouca pesca" (informação verbal). Entretanto, em momento algum foi desconsiderado, pelos pescadores, a importância dessa política na segurança da reprodução das espécies, e sim apenas questionado sobre a inadequação com a realidade da atividade.

Essas falhas são atribuídas, por Gasalla e Tutui (2000), à desconsideração dos problemas específicos de cada região na elaboração da norma proibitiva e do conhecimento tradicional da população pesqueira que está em contato direto com o recurso. Nesse contexto, os saberes são vistos como insuficientes e, em muitos casos, desvalorizados pela comunidade científica diante da não validação de uma realidade cotidiana vivenciada pelo pescador artesanal.

No entendimento de Diegues (2000), os pescadores artesanais possuem um conhecimento abrangente sobre a natureza e o ambiente que o cercam, bem como em relação às variações recorrentes que irão interferir na dinâmica da pesca. Diante disso, Castro (2000) ressalta que esses conhecimentos deveriam, sim, ser considerados, permitindo, desse modo, a adequação e o controle da relação entre produção e manutenção da natureza.

Outro ponto negativo, na visão de alguns pescadores, é a diminuição do volume da pesca, fato reforçado em praticamente todas as entrevistas. Fica assim evidenciado que a decadência da pesca na Lagoa dos Patos ocorre em razão de diversos fatores, como o efeito das condições climáticas, a poluição das águas, a sobrepesca praticada por grandes empresas e, novamente, a escassez da água salgada. Esses fatores também estão presentes no estudo realizado por Garcez e Sánchez-Botero (2005) sobre as comunidades de pescadores artesanais do estado do Rio Grande do Sul, mostrando que a diminuição gradativa dos estoques também vem incidindo em outras regiões do estado.

O problema da diminuição dos estoques está fortemente associado, sob a ótica dos pescadores, às condições climáticas, englobando os regimes de seca e de chuvas, e à entrada da água salgada na lagoa, como destacado anteriormente. Todavia, percebe-se, através dos depoimentos, que esse evento está correlacionado também com fatores como os altos níveis de poluição das águas da lagoa, fato que se vincula à destinação inadequada 


\section{OREVER}

do esgoto doméstico, dos agrotóxicos usados principalmente nas lavouras de arroz, bem como dos próprios resíduos da pesca. Além de diminuir os estoques de peixes, a poluição afeta a qualidade das espécies que ainda se desenvolvem no estuário, como se pode perceber no depoimento do entrevistado EXS:

Me criei com a Lagoa dos Patos com uma água doce clarinha, e hoje nós temos uma água que parece um barro. Aí vai ter algum plâncton no fundo?! O peixe vai comer toda essa imundícia que tem no fundo. Muitas espécies de peixes certas épocas, que sempre foram saudáveis, hoje tem época que quando você limpa, tu não aguenta o fedor (Pescador EXS, informação verbal, 2017).

Por fim, associado à poluição, também foi relatado o esforço de pesca, principalmente realizado pela pesca industrial. Essa modalidade possui um poder de captura maior, na qual se pratica uma pesca predatória, que impede, assim, a entrada de muitas espécies na Lagoa dos Patos, prejudicando toda a cadeia produtiva, e em alguns casos, desrespeitando regulamentos básicos (CENI, 2015). Esse fato acentua a vulnerabilidade dos pescadores artesanais diante da escassez dos meios que eles dispõem.

Os entrevistados reconhecem seu desacordo com a atuação da pesca industrial, pois, quando se perguntou sobre os motivos da mudança do volume da pesca, $45 \%$ das respostas ressaltaram o esforço de pesca industrial como responsável por essa situação. Os depoimentos abaixo destacam a visão predominante dos pescadores sobre a pesca industrial:

Aonde só tira e não bota vai diminuindo, mas não porque tá terminando o peixe, tá diminuindo pela quantidade de pescador. Esses pescadores prejudicam a gente, o peixe que a gente mata é de um quilo para cima, eles não, já começam a matar desde o filhotinho até o adulto (Pescador GN, informação verbal, 2017).

Isso é foi os barcos acabaram com tudo. Excesso de barco, não adianta querer condenar a barra lá, porque não é a barra não. O peixe quando tem que entrar ele entra, quando o bagre entrou na lagoa aí, e ficou empilhado não se pode matar, tá proibido (Pescador LCA, informação verbal, 2017).

Até aqui, todas as alusões tiveram como foco de análise as perspectivas dos pescadores em relação apenas aos problemas da atividade pesqueira. Entretanto, torna-se fundamental apresentar as medidas para melhorar a atividade, baseadas também nos depoimentos dos pescadores artesanais, as quais serão abordadas na seção seguinte. 


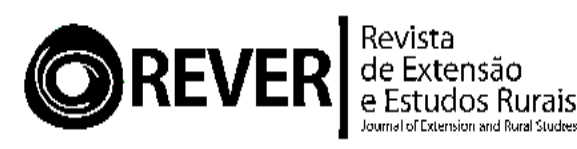

\section{Perspectiva dos pescadores em relação às medidas para melhorar a atividade pesqueira na Colônia Z-3}

Tendo em vista que anteriormente foram mostrados os principais problemas da atividade pesqueira, ressaltados pelos próprios pescadores artesanais da Colônia Z-3, torna-se fundamental identificar, através dos depoimentos, as medidas, por eles sugeridas, para melhorar a pesca extrativa nessa localidade.

Os dados da Tabela 3 indicam várias possibilidades, mas, entre mais de $60 \%$ das respostas, se destacam três caminhos ou alternativas de melhorias, quais sejam: mudança das leis em conjunto com os pescadores (31\%), elaboração de uma tabela de preço mínimo $(20,7 \%)$ e concessão de subsídio ao preço do óleo diesel para o pescador $(10,3 \%)$.

Merece atenção, primeiramente, as duas primeiras medidas mais sugeridas pelos os entrevistados: a mudança das leis considerando o entendimento dos pescadores quanto ao período de defeso e a criação de uma tabela de preço mínimo. A primeira alternativa demonstra o interesse dos próprios pescadores em participar da discussão e da alteração das leis, juntamente com os órgãos responsáveis. Os pescadores deixam claro que seus conhecimentos tradicionais deveriam ser valorizados nesse processo de transformação.

Porém, de acordo com Diegues (2004), a situação atual evidencia certo confronto entre os saberes tradicionais e os conhecimentos científicos. Entretanto, seria de suma importância o reconhecimento dos saberes tradicionais pelos órgãos governamentais e a associação de ambos, objetivando adequar e melhorar as leis que regem a utilização dos recursos pesqueiros. Como relatado por um dos entrevistados:

Fazer as leis com a participação do pescador, era uma das coisas que nós tinha que participar. Preservando na hora certa, não na hora errada como tá acontecendo (Pescador ACD, informação verbal, 2017).

A segunda, e não menos importante, medida de melhoria, referente à implementação da tabela de preço mínimo, está diretamente relacionada com um dos problemas mais ressaltados pelos entrevistados, qual seja: o preço baixo do pescado. Essa alternativa é muito semelhante à Política de Garantia de Preços Mínimos ${ }^{5}$ (PGPM), que tem a finalidade de assegurar uma remuneração mínima para os produtos agrícolas, diminuindo, assim, o efeito das oscilações dos preços na renda final dos produtores, o que é ressaltado nos depoimentos abaixo.

\footnotetext{
${ }^{5}$ A política de preços mínimos é praticada especialmente na área de grãos.
} 


\section{OREVER|}

O peixe ele é assim, se tem pouco ele é estipulado num certo valor né, se tem muito peixe, ele despenca lá em baixo. Por isso que eu digo se fosse um mínimo, menos do que isso não pode ser comercializado. Porque se dois, três mata um peixe o preço já cai lá em baixo, de dois reais vai lá pra setenta centavos. Quando tem bastante que tu tem como ganhar um pouco mais, ele se desvaloriza o preço (Pescador $\mathrm{ABC}$, informação verbal, 2017).

Eu acho assim, assim como eles garantiam o frango um preço mínimo eles tinham que garantir a pesca um preço mínimo. $\mathrm{O}$ arroz tem um preço mínimo, um monte de produto tem preço mínimo o peixe não tem. Eles compram ao preço que quiserem. Se tu chegar ali a tainha está dois reais, mas se tu matar muita tainha tu chega aqui eles só querem pagar um real, aí não tem condições e isso o governo não pensa (Pescador RRS, informação verbal, 2017).

Tabela 3: Principais medidas sugeridas pelos pescadores artesanais entrevistados da Colônia de Pescadores Z-3

\begin{tabular}{lcc}
\hline Principais medidas de melhoria da atividade & $\begin{array}{c}\text { Frequência } \\
\text { absoluta* }\end{array}$ & $\begin{array}{c}\text { Frequência } \\
\text { relativa } \\
(\mathbf{\%})\end{array}$ \\
\hline $\begin{array}{l}\text { Mudança das leis e do período de defeso, em conjunto com os } \\
\text { pescadores }\end{array}$ & 9 & 31,0 \\
\hline Tabela de preço mínimo & 6 & 20,7 \\
\hline Subsídio ao óleo diesel para o pescador & 3 & 10,3 \\
\hline Entrada de água salgada na lagoa & 2 & 6,9 \\
\hline Melhorias nos molhes & 2 & 6,9 \\
\hline Apoio político à atividade & 1 & 3,4 \\
\hline Conscientização ambiental & 1 & 3,4 \\
\hline $\begin{array}{l}\text { Conscientização do intermediário em relação ao preço do } \\
\text { produto }\end{array}$ & 1 & 3,4 \\
\hline Cooperativa & 1 & 3,4 \\
\hline Fiscalização da pesca industrial & 1 & 3,4 \\
\hline Indústria na Colônia Z-3 & 1 & 3,4 \\
\hline Infraestrutura da Colônia Z-3 & 1 & 3,4 \\
\hline
\end{tabular}

* Número de vezes em que esse tema se repetiu na fala dos entrevistados.

Fonte: Pesquisa de campo, 2017.

Apesar de a formulação de uma tabela de preço mínimo para os produtos oriundos da pesca ter sido uma alternativa muito citada pelos entrevistados $(20,7 \%)$ e ser uma solução supostamente vantajosa para os pescadores artesanais, através de alguns depoimentos, é possível perceber que essa realidade está longe de ser alcançada pela categoria, devido à falta de apoio governamental para estruturar e garantir a permanência dessa política.

Já tentemo definir o preço mínimo, mas não tem como segura, porque se o pescador começa a bater o pé e definir o preço ele não vem buscar, aí tem que jogar fora. E também o governo não vê isso, porque hoje em 


\section{OREVER|}

dia não tem um ministério pra pesca, nem uma secretaria pra pesca. Nós contribuimo tanto pro país como a agricultura né (Pescador RRS, informação verbal, 2017).

É mas hoje nós teria isso só em pensamento, nunca vamo te essa oportunidade de te alguém que se interessasse e fosse tabelado o preço justo pro pescador (Pescador EXS, informação verbal, 2017).

A última medida mais relatada refere-se à volta da concessão de subsídio ao óleo diesel para o pescador, principalmente o artesanal. Uma política pública adotada pelo governo reduziria os custos com o combustível, aumentando, consequentemente, a rentabilidade da pesca, visto que esse item representa entre $10 \%$ e $60 \%$ do custo total da atividade pesqueira (SOUZA, 2001). A última vez que essa política pública entrou em vigor no país foi no ano de 1997, quando o governo federal instituiu o Programa de Equalização Econômica do Óleo Diesel (MELO, 2012).

Apesar das inúmeras tentativas de retomada desse programa, ainda existem muitos obstáculos que dificultam sua eficácia econômica, como a demora no ressarcimento para a frota industrial, os entraves burocráticos e o desconhecimento dos instrumentos legais que autorizam a subvenção ao óleo diesel para o setor artesanal. De acordo com o pescador RRS, esse benefício deveria ser reativado devido ao fato de o:

Brasil ser o país que mais produz combustível no mundo, imagina $50 \%$ do combustível é imposto. Reduz o imposto pra pesca e a agricultura, estes não vão pagar imposto pra combustível (Pescador RRS, informação verbal, 2017).

Outra questão relevante, mas que não apareceu de forma muito significativa entre as medidas citadas pelos entrevistados, foi a conscientização ambiental $(3,4 \%)$, a qual tem grande impacto na atividade, que, como é sabido, depende diretamente da natureza para se desenvolver adequadamente. Há que se considerar que, atualmente, muitos pescadores estão em condições de vulnerabilidade social também em virtude do estado de deterioração dos recursos naturais, processo este agravado pela degradação de determinados elementos da natureza e pela poluição do ambiente (KALIKOSKI e VASCONCELLOS, 2013; FIGUEREDO et al., 2017).

Diante disso, de acordo com Andreoli (2007), a prática de inserir o tema da educação ambiental entre os pescadores e na comunidade em que estão inseridos abre uma janela de oportunidades para se repensar a importância de desenvolver soluções com vistas ao futuro, e também ao presente, dado que os efeitos já se fazem sentir na atual conjuntura. $\mathrm{O}$ mesmo autor, em sua obra, ressalta que os pescadores artesanais com um pouco mais de estudo percebem a grande importância da educação ambiental, haja vista que, muitas vezes, suas atitudes relacionadas à natureza são justificadas com base na falta 


\section{OREVER/|}

de conhecimento sobre o assunto. Concluindo, admite-se que é crucial investir na capacitação dos pescadores, evitando, desse modo, graves prejuízos ao patrimônio natural.

\section{Considerações finais}

O estudo estabeleceu como foco de análise a identificação, através dos depoimentos colhidos junto à comunidade de pescadores artesanais da Colônia Z-3, dos principais problemas da atividade pesqueira e, concomitantemente, das possíveis soluções para o enfrentamento das dificuldades encontradas ao se praticar tal atividade, segundo o prisma dos atores locais. A importância social deste estudo está mais do que justificada diante do grande número de pessoas que dependem desse ofício e da renda por ele gerada.

Os dados coletados permitiram destacar como principais problemas da atividade os efeitos produzidos pela escassez da água salgada, pelo baixo preço pago pelo pescado, pelas leis que regulam o setor, pelo período de defeso e pela diminuição do volume da pesca, e como possíveis soluções para as condições de vulnerabilidade em que se encontra a atividade, a realização de mudanças nas leis em conjunto com os pescadores. Além disso, tem-se a reivindicação de uma tabela de preço mínimo para os produtos oriundos da pesca e de uma política pública de subsídio ao preço do óleo diesel para o pescador.

Assim, o presente estudo se reveste de importância ao buscar ampliar o grau de conhecimento referente aos desafios que obstaculizam o desenvolvimento da pesca na Colônia Z-3, mostrando várias dificuldades, tanto no âmbito socioeconômico como no ambiental, que são enfrentadas nessa localidade de Pelotas. Além disso, permitiu analisar, sucintamente, o perfil socioeconômico dos pescadores da Colônia Z-3 entrevistados, a cadeia produtiva da pesca que engloba a atividade, bem como algumas particularidades ambientais, sociais e culturais da área de estudo.

Os dados apresentados também permitem supor que a legislação que rege a pesca não atende as demandas específicas da comunidade, haja vista que foi concebida para atender a todo o território nacional. Diante disso, é possível verificar que uma parcela de pescadores, em nosso país, burla o período de defeso estabelecido, por não condizer com a realidade do local. Por outra parte, as ações conduzidas pelo poder público municipal são absolutamente inócuas do ponto de vista da regulação ambiental.

Finalizando a presente reflexão, cabe ressaltar que essas considerações não pretendem esgotar o assunto, mas apenas contribuir para a discussão do tema e apontar 


\section{OREVER|}

caminhos para futuras pesquisas na área da pesca artesanal. No entanto, muito ainda necessita ser realizado através de outros estudos e monitoramento dessa atividade, sempre envolvendo a participação ativa de todos os agentes que intervêm direta ou indiretamente na atividade pesqueira.

\section{Referências bibliográficas}

ANDREOLI, V. M. Natureza e Pesca: Um estudo sobre os pescadores artesanais de Matinhos - PR. Dissertação (Mestrado Programa de Pós-Graduação em Sociologia). Paraná: UFPR, 2007.

BAUER, M. W.; GASKELL, G. Pesquisa Qualitativa com Texto, Imagem e Som. Um manual prático. Petrópolis: Editora Vozes, 2002.

BRAIODO, J. A.; CAPORLINGUA, V. H. Da cidadania ambiental à educação ambiental política: desafios na pesca artesanal em Rio Grande/RS e São José do Norte/rs. Revista Direito Ambiental e sociedade, v. 4, p. 179-205, 2005.

BRASIL. Instrução Normativa MPA n 06, de 29 de junho de 2012. Dispõe sobre os procedimentos administrativos para a inscrição de pessoas físicas no Registro Geral da Atividade Pesqueira na categoria de Pescador Profissional no âmbito do MPA. In: Diário Oficial da União, Brasília, 29 de junho de 2012.

CALLIARI, L. J. Aspectos Sedimentológicos e Ambientais da Região Sul da Laguna dos Patos. Dissertação (Mestrado Programa de Pós-Graduação em Geociências). Porto Alegre: UFRGS, 1980.

CARDOSO, P.O; DOULA, S.M. Reservas extrativistas marinhas: perspectivas e limitações para jovens pescadores. Acta Biológica Catarinense, 5(2):5-19, 2018.

CARDOSO, Poliana Oliveira; DOULA, Sheila Maria. Produção acadêmica sobre as reservas extrativistas brasileiras (2010 - 2015). Revista de Extensão e Estudos Rurais, v.5, p. 97, 2016.

CASTRO, E. Território, biodiversidade e saberes de populações tradicionais. In: DIEGUES, A. C. Etnoconservação: novos rumos para a proteção da natureza nos trópicos. São Paulo: HUCITEC e NUPAUB, 2000, p. 165-182.

CENI, G. Contribuição à Gestão Pesqueira da Laguna dos Patos, RS, Brasil. Tese (Doutorado Programa de Pós-Graduação em Zoologia). Porto Alegre: PUCRS, 2015.

CEREGATO, S.A.; PETRERE Jr, M. Aspectos sócio-econômicos das pescarias artesanais realizadas no complexo de Urubupungá e a sua jusante no Rio Paraná. HOLOS Environment, v. 2, p. 01-24, 2002.

DECKER, A. T. Gestão Socioambiental de Comunidade de Pescadores Artesanais: Colônia de Pescadores Z-3, Pelotas/RS. Dissertação (Mestrado Programa de Pós- 


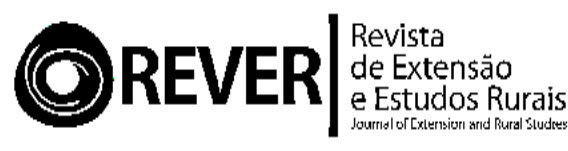

Graduação em Desenvolvimento Territorial e Sistemas Agroindustriais). Pelotas: UFPel, 2016.

DIEGUES. Etnoconservação - Novos Rumos para a Conservação da natureza. São Paulo: HUCITEC e NUPAUB-USP, 2000.

Conhecimento Tradicional e Apropriação Social do Ambiente Marinho. In: RODRIGUES, E., PAULA, A.C., ARAUJO, C.M. Roteiros Metodológicos: plano de Manejo de Uso Múltiplo das Reservas Extrativistas Federais. Brasília: IBAMA, 2004, p. 125-157.

FIGUEIRA. Colônia de Pescadores Z3, Pelotas - RS: da crise na pesca à expansão do turismo com base no Patrimônio Cultural. Dissertação (Mestrado Programa de Pósgraduação em Memória Social e Patrimônio Cultural). Pelotas: UFPel, 2009.

FIGUEREDO, Natália Aragão; FERREIRA NETO, José Ambrósio; BRAGA, Marcelo José; TEIXEIRA, Thais Helena. A economia verde como referência para análise das unidade de conservação de uso sustentável no estado do Pará, Brasil. Revista de Extensão e Estudos Rurais, v. 6, p. 40, 2017.

Food and Agriculture Organization - FAO. Expert consultation on the role of small-scale fisheries in poverty alleviation and food security. Roma, p. 116, nov. 1975. Disponível em: http://www.fao.org/docrep/017/h3100e/h3100e.pdf. Acesso em: 10 out. 2017.

El estado mundial de la pesca y la acuicultura. Roma, p. 224, 2016. Disponível em: http://www.fao.org/3/a-i5555s.pdf. Acesso em: 25 mar 2019.

GARCEZ, D. S.; SÁNCHEZ-BOTERO, J. I. Comunidades de pescadores artesanais no estado do Rio Grande do Sul, Brasil. Atlântica, v. 27, p. 17-29, 2005.

GASALLA, M.A. e TUTUI, S.L.S. 2000 Pesca responsável e conservação dos estoques pesqueiros costeiros: principais problemas no sudeste do Brasil. Anais... Vitória: ACIESP, 2000. p.148-159.

IBGE - Instituto Brasileiro de Geografia e Estatística. Pesquisa Nacional por Amostra de Domicílios Contínua (Pnad Contínua) no ano de 2016. Rio de Janeiro, 2016.

ISAAC-NAHUM, V.J. Explotação e manejo dos recursos pesqueiros do litoral Amazônico: um desafio para o futuro. Ciência e Cultura, v. 58, p. 33-36, 2006.

KALIKOSKI, D. C.; VASCONCELLOS, M. Estudo das condições técnicas, econômicas e ambientais da pesca de pequena escala no estuário da Lagoa dos Patos, Brasil: uma metodologia de avaliação. FAO, Circular de Pesca e Aquicultura, nº 1075, 200 p. 2013.

MELO, V. P. Políticas públicas e a sustentabilidade da pesca marinha no Brasil. Dissertação (Mestrado Programa de Pós-Graduação em Economia). Araraquara: UNESP, 2012.

Ministério da Pesca e Aquicultura MPA. A pesca no Brasil. Junho de 2014. 


\section{OREVER|}

MUSIELLO-FERNANDES, J.; ZAPPES, C. A.; HOSTIM-SILVA, M. Small-scale shrimp fisheries on the Brazilian coast: Stakeholders perceptions of the closed season and integrated management. Ocean \& Coastal Management, v. 148, p. 89-96, 2017.

Small-scale fisheries of the Atlantic seabob shrimp (Xiphopenaeuskroyeri): Continuity of commercialization and maintenance of the local culture through making public policies on the Brazilian coast. Ocean \& Coastal Management, v. 155, p. 76-82, 2018.

NIERDERLE, P. A.; GRISA, C. Transformações sócio-produtivas na pesca artesanal do estuário da lagoa dos Patos. Rev. Eletrônica Mestr. Educ. Ambiental. v. 16, p. 85-106, 2006.

PASQUOTTO, Vinicius Frizzo. Pesca artesanal no Rio Grande do Sul: os pescadores de São Lourenço do Sul e suas estratégias de reprodução social. Dissertação (Mestrado Programa de Pós-Graduação em Desenvolvimento Rural). Porto Alegre: UFRGS, 2005.

PETRERE Jr, M. WALTER, T.; MINTE-VERA, C. V. Income evaluation - scale fisher in two Brazilian urban reservoirs: Represa Billings (SP) and Lago Paranoá (DF). Brazilian Journal of Biology, v. 66, p. 817-828, 2006.

ROSA, Mário. Geografia de Pelotas. Pelotas, Editora UFPel, 1985.

SACCO DOS ANJOS, F. et al. Pesca artesanal e pluriatividade: o caso da Colônia Z-3 em Pelotas, RS. Sociedade em Debate, v. 10, p. 9-42, 2004.

SANTOS, M.A.S. A cadeia produtiva da pesca artesanal no estado do Para: estudo de caso no nordeste paraense. Amazônia: Ciência \& Desenvolvimento, v. 1, p. 61-81, 2005.

SEN, A. K. Desenvolvimento como Liberdade. São Paulo: Companhia das Letras, 2000.

SILVA, A. P. Pesca artesanal brasileira. Aspectos conceituais, históricos, institucionais e prospectivos. Boletim de Pesquisa e Desenvolvimento, Embrapa, Palmas, n. 1, p. 32, 2014.

SOUZA, M. A. A. Política e evolução da atividade pesqueira no Rio Grande do Sul: 1960 a 1997. Dissertação (Mestrado Programa de Pós-Graduação em Economia Rural). Porto Alegre: UFRGS, 2001.

WALTER, T. Ecologia da pesca artesanal no lago Paranoá. Dissertação (Mestrado Programa de Pós-Graduação em Engenharia Ambiental). São Paulo: USP, 2000. 